\title{
The relationship between cortisol and IGF-I influences metabolic alteration in pediatric overweight and obesity
}

\author{
Roberta Ricotti', Arianna Solito ${ }^{1}$, Elena Mariotti Zani' ${ }^{2}$, Marina Caputo ${ }^{2}$, Giulia Genoni' \\ Francesco Barone-Adesi ${ }^{3}$, Valentina Mancioppi', Emanuela Agosti ${ }^{2}$, \\ Gianluca Aimaretti ${ }^{2}$, Simonetta Bellone ${ }^{1}$ and Flavia Prodam ${ }^{1,2,4}$
}

${ }^{1}$ SCDU of Pediatrics, Department of Health Sciences, ${ }^{2}$ SCDU of Endocrinology, Department of Translational Medicine, ${ }^{3}$ Epidemiology, Department of Translational Medicine, and ${ }^{4}$ Interdisciplinary Research Center of Autoimmune and Allergic Diseases, University of Piemonte Orientale, Novara, Italy

\begin{abstract}
Background/objective: Data on metabolic impairments in Cushing's syndrome and GH deficiency all suggest that the relationship between cortisol and GH/IGF-I axis in obesity may have a role in the related diseases. However, studies focusing only on one of these hormones are often controversial in paediatrics. We aimed to explore the simultaneous relationship between cortisol and IGF-I with the metabolic alterations in paediatric obesity.

Subjects/methods: Retrospective cross-sectional study in a tertiary care center. We recruited 876 (441 males and 435 females) overweight and obese children and adolescents. A complete clinical and biochemical evaluation including OGTT was performed. Cortisol and IGF-I SDS were divided in quartiles and then crossed to explore the reciprocal influence of high/high, low/low, and high/low levels of each one on the metabolic alterations of obesity. Results: Subjects in the higher quartiles of IGF-I-SDS and cortisol had an increased risk of hypertension, hypercholesterolemia, high levels of triglycerides, and reduced HDL cholesterol. Diversely, lower IGF-I-SDS quartiles were associated with higher blood glucose, insulin, insulin resistance, and reduced insulin sensitivity levels with the rise of cortisol quartiles.

Conclusions: We observed that apart from glucose metabolism that is associated with low IGF-I and high cortisol levels, the other parameters known to be associated with increased cardiovascular risk were related to high levels of both IGF-I and cortisol, even if within normal range. Cortisol and IGF-I play a complex role in the comorbidities of obesity, and the evaluation of both variables could clarify some of the discordant results.
\end{abstract}

\section{Introduction}

Obesity is associated with a complex derangement of the endocrine regulation due to compensatory mechanisms. Many of them can have a role in the development of persistent metabolic alterations, resulting in the metabolic unhealthy obese phenotype.

Several studies have shown that abdominal obesity, hypertension, high triglycerides, and low HDL cholesterol levels are associated with functional hypercortisolism
$(1,2,3)$, suggesting that a pharmacological inhibition of cortisol could be a valid option to avoid these kinds of complications $(4,5)$. We also recently demonstrated in children that ACTH and cortisol are differently associated with the risk of comorbidities in children and adolescents (6).

Moreover, obesity is associated with functional alterations of GH/IGF-I axis in obese subjects, a reduction

Published by Bioscientifica Ltd. 
of GH levels has been detected both at baseline and in dynamic tests and weight loss rescues normal values (7). Although GH secretion is blunted, the dysregulation of the IGF-I system in obesity is uncertain, since IGF-I is detected as low, normal, or elevated, also in the paediatric age $(8,9,10,11)$. Population studies in adults show that IGF-I secretion is dependent on BMI with an inverse U-shaped curve and higher levels between a BMI of 30-35 $\mathrm{kg} / \mathrm{m}^{2}$, representing a critical metabolic and nutrientsensing regulator (12). Furthermore, the interaction with several comorbidities is complex with direct or curvilinear associations (13), also influencing mortality (14).

The regulation of IGF-I in obesity is complex and many factors have a role, such as hypothalamic neuropeptides, ghrelin, insulin, circulating free fatty acids, and cortisol (11). Among the several players involved, both chronically raised cortisol levels and relative hypoadrenalism are associated with an impaired GH secretion, suggesting a dual dose-dependent effect (15). On the other hand, GH and IGF-I influence 1 1 -hydroxysteroid dehydrogenase 1 activity in many organs, including adipose tissue and pancreas (5).

This evidence and data on metabolic impairments present in Cushing's syndrome and GH deficiency suggest that the relationship between cortisol and GH/IGF-I axis in obesity may have a role in the associated health diseases. Based on this hypothesis, the aim of this study is to explore the relationship between IGF-I and cortisol by crossing their quartiles with the metabolic alterations in paediatric obesity.

\section{Methods}

\section{Study design and population}

This was a cross sectional study. Data of 900 subjects, referred to the Paediatric Endocrine Service of our hospital for overweight and obesity, were collected from January 2005 to December 2016. Eligibility criteria were a general healthy status and overweight or obesity. Subjects with prior engagement in diet programs were excluded from the study. Other exclusion criteria were diagnosis of diabetes, high blood pressure (BP), use of drugs influencing glucose or lipid metabolism, endocrine or genetic obesity, prematurity, distress during blood sampling, and problematic phlebotomy (more than $5 \mathrm{~min}$ ). The protocol was conducted in accordance with the declaration of Helsinki and approved by the Local Inter-Hospital Ethic Committee (Maggiore Hospital Ethical Committee, n. 95/12). All parents gave prior informed consent, and careful explanations were provided to each patient.

\section{Clinical measurements and biochemical analysis}

Waist circumference, blood pressure levels, fasting and post-oral glucose tolerance test, glucose levels, insulin resistance, lipid profile, and liver enzymes were all considered as cardiometabolic risk factors.

Pubertal stages were determined by a physical examination, using the criteria of Marshall and Tanner $(1,2,3,4,5,16)$. Height was measured three times to the nearest $0.1 \mathrm{~cm}$ using the Harpenden stadiometer, and body weight with light clothing was assessed to the nearest $0.1 \mathrm{~kg}$ using a manual weighing scale. BMI was calculated as body weight divided by squared height $(\mathrm{kg} /$ $\mathrm{m}^{2}$ ). BMI deviation score (BMI z-score) was calculated by L, M, S method (17). All data were classified according to IOTF criteria (17). Waist circumference was measured in the area between the ribs and the iliac crest at the lowest horizontal circumference, while hip circumference at the level of the imaginary horizontal circumference passing through the femoral trochanters, in standing position, at the end of a normal breath. Both were recorded to the nearest $0.1 \mathrm{~cm}$. Waist/height ratio was calculated as well.

Systolic BP (SBP) and diastolic BP (DBP), classified according to the American Paediatric Society's Guidelines (18), were measured three times at the right arm with participants seated quietly for at least 5 min using a standard digital oscillometric sphygmomanometer.

Blood samples were collected after $12 \mathrm{~h}$ of fasting in order to assess cortisol, insulin-like growth factor-I (IGF-I), alanine- (ALT), aspartate-aminotransferase (AST), glucose, insulin, total cholesterol, HDL cholesterol, and triglycerides. Low-density lipoprotein (LDL) cholesterol was calculated using the Friedwald formula. Obese subjects also underwent an oral glucose tolerance test (OGTT; $1.75 \mathrm{~g}$ of glucose solution per kg, maximum $75 \mathrm{~g}$ ). Plasma samples were immediately processed and stored at $-80^{\circ} \mathrm{C}$. All participants were evaluated for signs suggestive of Cushing's syndrome, according to the Endocrine Society's Guidelines (19). In case of positive screening, a $1 \mathrm{mg}$ overnight dexamethasone suppression test and urinary free cortisol measurement were performed.

Cortisol levels $(\mu \mathrm{g} / \mathrm{dL})$ were measured by LIAISON Analyzer with the SPALT principle (Solid Phase Antigen Linked Technique). Inter- and intra-assay coefficients of variation were 3.5 and $3.2 \%$ respectively with an analytical sensitivity of $0.16 \mu \mathrm{g} / \mathrm{dL}$. 
Serum IGF-I values were measured by LIAISON Analyzer with a chemo-luminescence (CLIA) method and an analytical sensitivity less than $3 \mathrm{ng} / \mathrm{mL}$. IGF-I s.D. score (IGF-I SDS) was calculated. Other analytical methods on ALT, AST, glucose, insulin, total cholesterol, HDL-cholesterol, and triglycerides were previously published $(20,21)$.

\section{Definitions}

Hypertension was defined $\geq 95$ th percentile for sex and age, as suggested by National High Blood Pressure Education Program Working Group of American Academy of Pediatrics (18).

Impaired fasting glucose (IFG), impaired glucose tolerance (IGT), and type 2 diabetes were defined according to American Diabetes Association (22). Using OGTT parameters, HOMA-IR, the Quantitative Insulinsensitivity Check Index (QUICKI), and insulin sensitivity obtained from the Matsuda Index (ISI) were calculated. Formulas have been previously reported (23).

\section{Statistical analysis}

All data are expressed as mean \pm s.D., absolute values, or percentages. Skewed variables were logarithmically transformed. Student $t$-test was used to investigate sex differences. IGF-ISDS and cortisollevelswere categorisedinto quartiles. The ANOVA was used to evaluate the association among continuous clinical and metabolic variables (BMI, BMI Z-score, weight and waist circumference, SBP, DBP, total cholesterol, HDL cholesterol, LDL cholesterol, triglycerides, fasting glucose levels, glucose levels at 120 min after the OGTT, fasting insulin, HOMA-IR, QUICKI, ISI index, AST, and ALT), cortisol, and IGF-I SDS quartiles. The ANOVA was also adjusted by confounding factors (Model 2: sex, age, Tanner stage, BMI, and waist circumference; Model 3: Model 2+HOMA-IR). Among each IGF1-SDS quartile, logistic regression has been performed in order to calculate the association between cortisol quartiles and the odd ratio (OR, 95\% IC) of each cardiovascular risk factor (hypertension, IFG, IGT, LDL-cholesterol $>75$ th percentile, HDL cholesterol $\leq 10$ th percentile, and triglycerides $\geq 90$ th percentile). Cortisol quartiles were analysed as independent variables with the first quartile as reference. The analysis was adjusted for the same covariates used in the previous Model 3. Statistical significance was set up for $P<0.05$. Samples ranging from 20 to 202 individuals have been estimated enough to demonstrate a difference of $20 \%$ in predicted prevalence of metabolic alterations across quartiles with $90 \%$ power and a significance level of
95\% basing on our previous data. Because the prevalence of glucose alterations is relatively low in paediatric obesity, a reduction of $20 \%$ in HOMA-IR with a s.D. of 1.8 has been considered (6). Statistical analysis was performed with SPSS for Windows version 17.0 (SPSS Inc.).

\section{Results}

\section{Population}

The final dataset included 876 patients (441 males and 435 females). Twenty-four children were excluded because they did not satisfy inclusion criteria (18 with a difficult blood sampling, 3 with hypothyroidism, and 3 with signs of infections at blood count cells). Clinical, biochemical, and hormonal characteristics of the population, stratified for sex, are reported in Table 1. Among them, 405 (46.1\%) subjects were prepubertal and 471 (53.8\%) were pubertal. Moreover, 215 (24.5\%) subjects were overweight and 661 (75.5\%) obese (271 of them were severely obese), according to the IOTF criteria, without a sex imbalance. Most of the population presented visceral obesity, in particular 841 (96\%) subjects had a waist circumference $\geq 90$ th percentile. Of the total cohort, 522 (59.6\%) subjects had hypertension and 77 (8.8\%) IFG or IGT. Nobody had type 2 diabetes. Levels of triglycerides $\geq 90$ th percentile and HDL $\leq 10$ th percentile were more frequent in boys.

Cortisol levels were lower than $5 \mu \mathrm{g} / \mathrm{dL}$ in 65 subjects, and 40 of them repeated the measurement with normal values, whereas the other 25 subjects underwent the dynamic test with a normal response (24). Nobody had IGF-I levels and a phenotype suggestive for GH deficiency.

\section{Associations among cortisol, IGF-I SDS quartiles, and cardio-metabolic parameters}

Patients have been divided into IGF-I SDS and cortisol quartiles. Each quartile included 219 subjects. Then, we crossed quartiles in order to evaluate the influence of both quartiles on the cardiovascular and metabolic risk factors. Subjects have been classified into 16 groups based on the IGF-1 SDS and cortisol quartiles, as shown in Supplementary Table 1 (see section on supplementary materials given at the end of this article).

BMI, BMI Z-score, weight, and waist circumference were similar in all cortisol and IGF-I SDS quartiles. In Models 1 and 2, age was positively correlated with the rise of cortisol quartiles of subjects in I and II quartiles of IGF-I SDS (I quartile $P<0.05$; II quartile $P<0.01$ ). 
Table 1 Biochemical and clinical characteristics of subjects.

\begin{tabular}{l}
\hline \\
\hline Age \\
Prepubertal \\
Pubertal \\
BMI Z-score $\left(\mathrm{kg} / \mathrm{m}^{2}\right)$ \\
BMI $\left(\mathrm{kg} / \mathrm{m}^{2}\right)$ \\
Waist circumference $(\mathrm{cm})$ \\
SBP $(\mathrm{mmHg})$ \\
DBP $(\mathrm{mmHg})$ \\
SBP/DBP $>95^{\circ}$ \\
Total cholesterol (mg/dL) \\
HDL (mg/dL) \\
TG (mg/dL) \\
LDL (mg/dL) \\
GICO' $(\mathrm{mg} / \mathrm{dL})$ \\
GIc120' $(\mathrm{mg} / \mathrm{dL})$ \\
Insulino' $(\mu U \mathrm{~d} / \mathrm{mL})$ \\
HOMA-IR \\
ISI \\
QUICKI \\
AST (IU/L) \\
ALT (IU/L) \\
Cortisol $(\mu g / \mathrm{dL})$ \\
IGF-1 $(\mathrm{ng} / \mathrm{mL})$ \\
IGF-1 SDS \\
\hline
\end{tabular}

\begin{tabular}{c}
\hline All $(n=876)$ \\
$10.6 \pm 3.2$ \\
$405(46.1 \%)$ \\
$471(53.8 \%)$ \\
$2.0 \pm 0.5$ \\
$27.0 \pm 4.7$ \\
$88.1 \pm 13.6$ \\
$124.8 \pm 16.2$ \\
$79.7 \pm 11.1$ \\
$522(59.6 \%)$ \\
$145.1 \pm 26.8$ \\
$43.2 \pm 9.8$ \\
$75.3 \pm 42.7$ \\
$86.7 \pm 22.6$ \\
$86.5 \pm 8.8$ \\
$108.9 \pm 18.9$ \\
$14.3 \pm 9.8$ \\
$3.2 \pm 2.4$ \\
$4.33 \pm 3.92$ \\
$0.34 \pm 0.06$ \\
$24.2 \pm 7.8$ \\
$23.8 \pm 13.3$ \\
$11.3 \pm 5.2$ \\
$268.5 \pm 121.4$ \\
$0.15 \pm 0.61$ \\
\end{tabular}

\begin{tabular}{c}
\hline $\mathbf{M}(n=441)$ \\
$10.6 \pm 2.9$ \\
$246 *(55.8 \%)$ \\
$195 *(44.2 \%)$ \\
$2.0 \pm 0.5$ \\
$27.1 \pm 4.4$ \\
$88.8 \pm 13.0$ \\
$125.9 \pm 16.4$ \\
$80.6 \pm 10.9$ \\
$270(61.2 \%)$ \\
$144.0 \pm 26.5$ \\
$42.9 \pm 9.3$ \\
$72.8 \pm 39.5$ \\
$86.4 \pm 22.5$ \\
$87.5 \pm 9.0$ \\
$110.2 \pm 18.4$ \\
$13.4 \pm 8.5$ \\
$3.0 \pm 2.2$ \\
$4.40 \pm 3.41$ \\
$0.34 \pm 0.04$ \\
$25.4 \pm 8.3$ \\
$25.9 \pm 16.0$ \\
$11.3 \pm 5.0$ \\
$237.8 \pm 113.3$ \\
$0.01 \pm 0.58$
\end{tabular}

\begin{tabular}{c}
\hline $\mathbf{F}(n=435)$ \\
\hline $10.7 \pm 3.4$ \\
$159^{*}(36.6 \%)$ \\
$276^{*}(63.4 \%)$ \\
$2.0 \pm 0.6$ \\
$26.9 \pm 5.0$ \\
$87.4 \pm 14.2$ \\
$123.7 \pm 15.91$ \\
$78.9 \pm 11.2$ \\
$252(57.9 \%)$ \\
$146.2 \pm 27.1$ \\
$43.5 \pm 10.2$ \\
$77.8 \pm 45.7$ \\
$87.0 \pm 22.8$ \\
$85.4 \pm 8.3$ \\
$107.6 \pm 19.3$ \\
$15.3 \pm 10.9$ \\
$3.3 \pm 2.5$ \\
$4.27 \pm 5.34$ \\
$0.34 \pm 0.05$ \\
$22.9 \pm 7.2$ \\
$21.6 \pm 9.2$ \\
$11.3 \pm 5.5$ \\
$299.6 \pm 121.5$ \\
$0.30 \pm 0.61$ \\
\end{tabular}

Significant differences between males and females: $* P<0.001, * \star P<0.003$. All data are expressed as mean \pm S.D. , absolute values, or percentages. ALT, alanine amino transferase; AST, aspartate amino transferase; DBP, diastolic blood pressure; glc0', fasting plasma glucose, glc120', blood glucose after 120 min of oral glucose tolerance test; HDL, High density lipoprotein; HOMA-IR, homeostatic model assessment insulin resistance; IGF-1 SDS, insulin-like growth factor-1 S.D. score; Ins0', fasting insulin; ISI, insulin sensitivity index; LDL, low density lipoprotein; QUICKI, quantitative insulin sensitivity index; SBP, systolic blood pressure; TG, triglycerides.

SBP increased with cortisol quartiles in all the IGF-I SDS quartiles in all the models (Model 3: I IGF-I SDS quartile: $P<0.02$; II IGF-I SDS quartile: $P<0.02$; III quartile: $P<0.01$; IV quartile: $P<0.02$ ). Diversely, DBP did not vary at the increase of cortisol quartiles, independently from IGF-I SDS quartiles and model.

Total cholesterol was positively associated with cortisol into high levels of IGF-I SDS in all the models (IV quartile, Model 3: $P<0.01$ ). The same trend was observed in the II quartile of IGF-I SDS only in Model 2 $(P=0.056)$

HDL cholesterol level did not change with the increase of IGF-I SDS and cortisol quartiles in the crude model, while assuming significance and increasing with the rise of cortisol quartiles in IV IGF-1 SDS quartile in Models $2(P<0.02)$ and $3(P<0.02)$.

LDL cholesterol was positively correlated with cortisol quartiles in IV IGF-I SDS quartile in Models 1 and 2 $(P<0.02)$, diversely by Model 3 .

Triglycerides increased with cortisol quartiles in I and IV IGF-I SDS quartile $(P<0.01)$ in both Models 1 and 2. On the other hand, by using Model 3 , the significance was maintained only in IV IGF-1 SDS quartile $(P<0.01)$ (Fig. 1$)$.

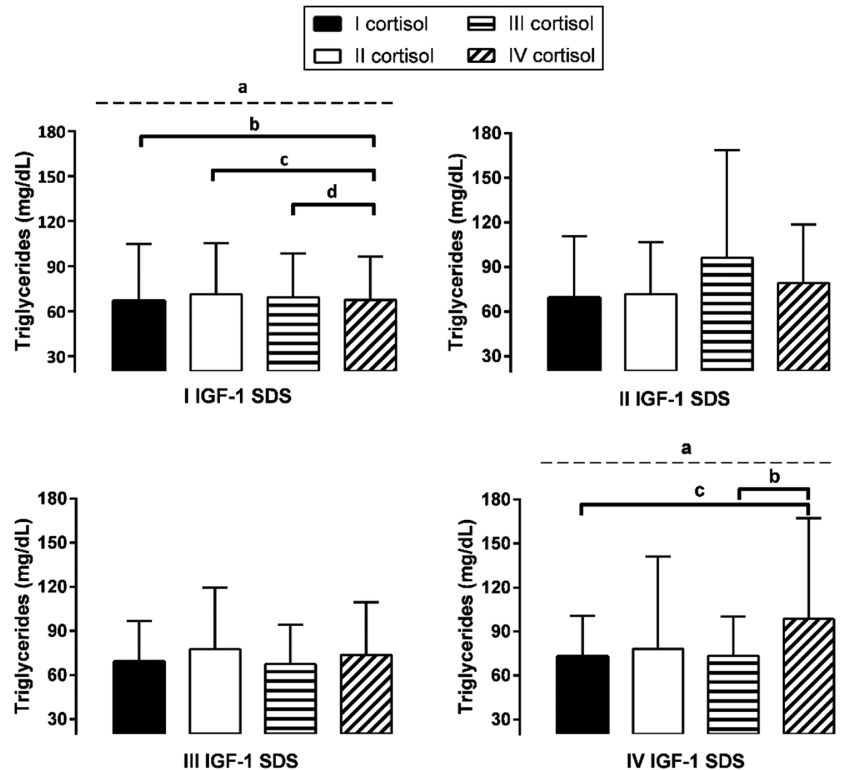

Figure 1

Triglycerides (mean \pm S.D.) in the I (A: $P<0.01$ in Model 2; $\mathrm{B}$ : $P<0.01, \mathrm{C}: P<0.02$, and $\mathrm{D}: P<0.01$ in Model 1 ), II, III, and IV IGF-1 SDS quartile (A: $P<0.01$ in Model 3; B: $P<0.05$, and C: $P<0.02$ in Model 1). 
Fasting glucose levels increased according to the increase of cortisol quartiles in I IGF-I SDS quartile $(P<0.05)$ and in IV IGF-I SDS quartile $(P<0.02)$ in Model 1. In Models 2 and 3, this significance was lost, while that in II IGF-I SDS quartile was obtained $(P<0.03)$. Regarding glucose levels at $120 \mathrm{~min}$ after the OGTT, there was no significance in any IGF-I SDS quartile.

Fasting insulin was positively correlated with cortisol in I IGF-I SDS quartile $(P<0.03)$ in the crude model but this was lost when covariates were inserted. Diversely, insulin resistance at fasting, expressed as HOMA-IR, and insulin sensitivity at fasting, expressed as QUICKI, increased and decreased, respectively, with the increase of cortisol quartiles in I IGF1-SDS quartile in all models (HOMA-IR: $P<0.04$; QUICKI: $P<0.05$ ) (Fig. 2). Similarly, ISI index decreased with the increase of cortisol quartiles in I quartile of IGF1-SDS (Model 1: $P<0.04$ ).

AST values increased with the increase of cortisol in I $(P<0.05)$ and III IGF-I SDS quartile in all the models (Models 1 and 2: $P<0.008$; Model 3: $P<0.01$ ), meanwhile ALT values increased with the rise of cortisol quartiles only in IV IGF-1 SDS (Models 1 and 2: $P<0.03$; Model 3: $P<0.04$ ).

\section{Associations among cortisol, IGF-I SDS quartiles, and metabolic alterations}

Subjects included in the III IGF-I SDS quartile had a high risk of hypertension in III (OR: 2.665, CI 95\% 1.029-6.900,

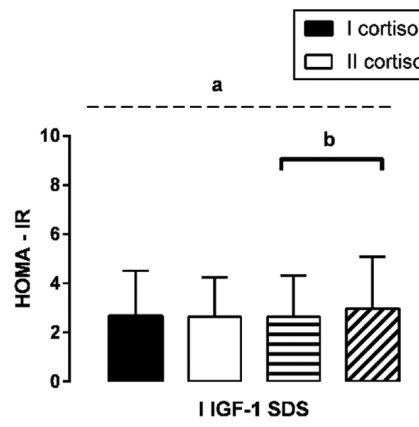

$$
\text { 曰 III cortisol }
$$
Z IV cortisol
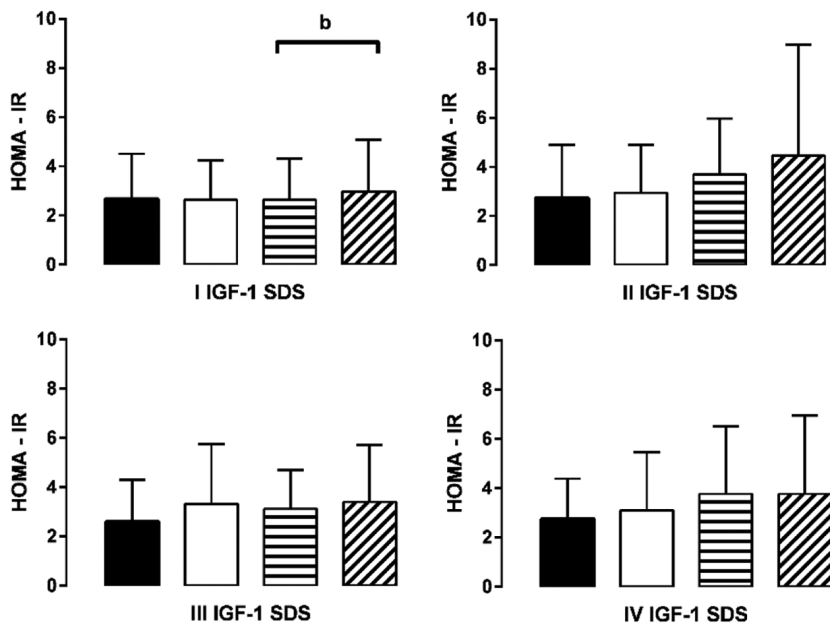

II IGF-1 SDS

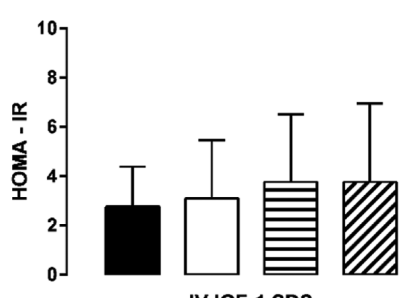

IV IGF-1 SDS
$P<0.04$ ) and IV cortisol quartile (OR: 2.700, CI 95\% 1.069-6.819, $P<0.03$ ).

The risk of high levels of total cholesterol increased within III and IV cortisol quartiles in subjects in II, III, and IV IGF-I SDS quartiles (Table 2).

Subjects included in the IV IGF-I SDS quartile had a higher risk of having HDL cholesterol $\leq 10$ th percentile when cortisol levels were in III (OR: 4.048, CI 95\% 1.56010.505, $P<0.004$ ) and IV quartile (OR: 1.238, CI 95\% 1.005-3.031, $P<0.05)$.

The risk of having triglycerides $\geq 90$ th percentile increased in the IV cortisol quartile (OR: 3.291, CI 95\% 1.117-9.698, $P<0.03$ ) in the I IGF-I SDS quartile.

No significance was detected for IFG or IGT presence.

\section{Discussion}

Obesity is strongly associated with several comorbidities, including modification of hypothalamic-pituitaryadrenal (HPA) and GH/IGF-I axis. The development of cardiovascular diseases begins in paediatric age; therefore, the aim of the present study was to verify the presence of a possible association between cortisol, IGF-I values, and obesity-related complications in overweight and obese patients.

The data herein presented showed an association between different metabolic parameters, cortisol, and IGF-I SDS. Although our results establish the usual cardiovascular and metabolic cluster, they differ from previous results in some variables between the lowest and the highest level of IGF-I. These differences can be due to a different evaluation of the complex metabolic relationship between HPA and GH/IGF-1 axis.

First, despite an expected association based on literature $(25,26,27)$, in our study, weight, BMI, BMI Z-score, and waist circumference did not vary in correspondence of an increase in cortisol and IGF-I SDS. However, discordant findings could partly derive from different inclusion criteria. Studies that reported associations of cortisol or IGF-I values with BMI and waist circumference included a normal-weight group of subjects, although often limited in dimension (25), or obese subjects belonging to a specific ethnic background (28). Other studies found an association only when daily urinary cortisol, urinary steroid metabolites or IGF-I binding proteins $(27,29)$ or more precise measures of fat mass were considered (3). Furthermore, during the paediatric age, HPA and GH/ IGF-I axis regulation can be influenced by other factors, including obesity comorbidities.

\section{Figure 2}

HOMA Index (mean \pm S.D.) in the I $(A: P<0.05$ in the Model 2; $\mathrm{B}$ : $P<0.02$ in Model 1), II, III, and IV IGF-1 SDS quartile. 
Table 2 Logistic regression of LDL cholesterol $\geq 75$ per centile in quartiles of cortisol ( $\mu \mathrm{g} / \mathrm{dL}$ ) and IGF-1 SDS quartiles.

\begin{tabular}{|c|c|c|c|c|c|}
\hline & \multicolumn{5}{|c|}{ LDL $\geq 75$ Percentile } \\
\hline & \multicolumn{4}{|c|}{ Cortisol quartiles } & \\
\hline & 1 & II & III & IV & \\
\hline I IGF1-SDS & & & & & \multirow[t]{3}{*}{$\chi^{2}=2.915 ; P=n s$} \\
\hline OR $(95 \% \mathrm{Cl})$ & 1.000 & $0.642(0.563-2.534)$ & $1.041(0.277-3.913)$ & $1.823(0.503-6.609)$ & \\
\hline$P$-value & & $n s$ & $n s$ & $n s$ & \\
\hline II IGF1-SDS & & & & & \multirow[t]{3}{*}{$\chi^{2}=9.633 ; P<0.02$} \\
\hline OR $(95 \% \mathrm{CI})$ & 1.000 & $1.347(0.371-4.887)$ & $4.042(1.280-12.771)$ & $4.177(1.38-15.336)$ & \\
\hline$P$-value & & $n s$ & $<0.01$ & $<0.03$ & \\
\hline III IGF1-SDS & & & & & \multirow[t]{3}{*}{$\chi^{2}=5.432 ; P=n s$} \\
\hline OR $(95 \% \mathrm{Cl})$ & 1.000 & $2.597(0.690-9.781)$ & $1.781(0.410-7.738)$ & 4.096 (1.167-14.382) & \\
\hline$P$-value & & $n s$ & $n s$ & 0.02 & \\
\hline IV IGF1-SDS & & & & & \multirow[t]{3}{*}{$\chi^{2}=8.127 ; P=n s$} \\
\hline OR $(95 \% \mathrm{CI})$ & 1.000 & $1.431(0.454-4.507)$ & 2.911 (1.164-8.791) & $1.879(0.562-6.285)$ & \\
\hline$P$-value & & $n s$ & $<0.05$ & $n s$ & \\
\hline
\end{tabular}

Values in boldface represent significant results. Cortisol values were subdivided into quartiles as follows: I $\leq 7.3 \mu \mathrm{g} / \mathrm{dL}, \mathrm{II}: 7.4-10.2 \mu \mathrm{g} / \mathrm{dL}, \mathrm{III}: 10.3-14.4 \mu \mathrm{g} /$ $\mathrm{dL}$, and IV: $>14.4 \mu \mathrm{g} / \mathrm{dL}$. The values of IGF-1 SDS were divided into quartiles as follows: I: $\leq-0.242, \mathrm{II}: 0.243-0.078$, III: 0.0079-0.045, and IV: >0.045. The variables used in Model 3 were: gender, age, Tanner stage, BMI Log, HOMA, and waist circumference.

We introduced several factors to explain, at least partially, how metabolic parameters, cortisol, and IGF-I interact. We demonstrated that SBP increases significantly, when cortisol increases in all the IGF-I SDS quartiles as well as the risk of hypertension exists in the III IGF-I SDS quartile for the highest levels of cortisol. IGF-I levels have been associated to the risk of hypertension both in condition of GH or IGF-I deficiency and acromegaly (30, 31). Three mechanisms could have a major role: (i.) the lack of the stimulation of the production of nitric oxide, increasing vasodilation, and reducing platelet activation for the low levels of IGF-I (32), (ii.) the stimulation of stiffening and vasoconstriction of vessel muscle cells and progression of atherosclerotic disease $(33,34)$, and (iii.) the augmented sodium retention with the increase of circulating volume (35) for the high levels. In literature, some discordant results are present. Similar (31), higher $(36,37)$, or lower $(38)$ IGF-I levels have been shown in hypertensive patients compared to normotensive ones. Recently, a Dutch study reported a U-shaped association between IGF-I levels and cardiovascular risk factors (39), partly in accordance with our results. Apart from IGF-I levels, we clearly showed that high SBP levels and risk of hypertension is present when cortisol levels are in the highest range of the normal values, suggesting that cortisol plays a decisive role in hypertension. Various mechanisms contribute to blood pressure increase: among the main ones, there is mineralocorticoid activity of cortisol. In hypercortisolism, renin-angiotensinaldosterone system is altered, secondary to both central and peripheral over-expression of angiotensin II receptors (40). Moreover, cortisol induces a reduction in nitric oxide synthesis, inhibiting activity of nitric oxide synthase (41), against what IGF-I usually causes. Moreover, other studies in obese children identified correlation between increased SBP and cortisol $(6,28,42)$. As a result, some contrasting data in literature on IGF-I could be relative to the cortisol balance.

With regard to lipid profile, total cholesterol, LDL-, HDL-cholesterol, and triglycerides increased with the rise in cortisol levels with high IGF-1. This has been confirmed also in the logistic regression analysis, where an increased risk of hypercholesterolemia and hypertriglyceridemia with cortisol values $\geq 10.2 \mu \mathrm{g} / \mathrm{dL}$ (III and IV quartile) was highlighted. This result agrees with literature data: activation of HPA axis can promote alteration of lipid profile in both adults (43) and children (6) due to complex mechanisms, involving the recycling of lipids, acting on the liver and adipose tissue $(44,45)$. Triglycerides level is the only variable that increased also in patients with low levels of IGF-I with the rise of cortisol. Low levels of IGF-I have a burden on cardiac and metabolic risk factors, increasing over production of triglycerides also in paediatric obesity (46).

An intriguing association is that on HDL-cholesterol. We showed that HDL-cholesterol increased with the rise of cortisol levels with high IGF-I, but subjects in the IV IGF-I SDS quartile had, however, an increased risk of HDLcholesterol $\leq 10$ th percentile when cortisol levels were high. Two different physiological mechanisms could be hypothesized. Considering the role of IGF-I, a positive association between IGF-I and HDL-cholesterol values was found in several studies, including one in obese adolescents (47). The exact mechanism underlying the 
relationship between IGF-I and HDL cholesterol in obesity is not fully clarified: the main reason may be that IGF-I inhibits the hepatic expression of the class B1 scavenger receptor on the surface of the hepatocytes, causing a reduction in the hepatic intake of HDL cholesterol and an increase in its circulating levels (48). Furthermore, by considering cortisol, it has been highlighted that the adrenal gland uses cholesterol contained in HDL and not the one contained in LDL to synthesize steroid hormones $(49,50)$. Indeed, patients with low levels of HDL had a low response to the ACTH test, suggesting that a condition of partial adrenal insufficiency should be related to a reduction of HDL cholesterol (51). On the other hand, subjects in the IV IGF-I SDS quartile with highest cortisol levels had an increased risk of HDL cholesterol $\leq 10$ th percentile when cortisol levels were high. We cannot exclude that, in the context of obesity, the state of lowgrade inflammation associated with cortisol as well as hyper-nutrition is able to stimulate a pro-atherogenic lipid profile even in the paediatric age $(52,53)$. However, also a statistical bias could be hypothesized, linked to the sample size, although it resulted enough for all the cardiometabolic alterations considered or to the lack of a control group of normal-weight children.

Regarding glucose metabolism, diversely by other factors discussed until now, we showed that fasting glucose and insulin resistance augmented and in correspondence of that, QUICKI and ISI decreased with high cortisol levels in the I IGF-I SDS quartile. This result could be linked to the failure of insulin-like activity of IGF-I when its levels are low, resulting in an altered glycaemic and insulin status. Indeed, IGF-I can stimulate the use of glucose by activating GLUT4 and inhibiting gluconeogenesis, all insulin-like effects that improve insulin sensitivity (54). The absence of an association between fasting glucose and insulin resistance, with the increase of cortisol quartiles in IV of IGF-I SDS quartile, could be an attempt to overcome a condition of subtle hyperglycaemia and hyperinsulinemia resulting from obesity. This would be through by stimulating IGF-I secretion and exploiting its hypoglycaemic effects (27). Diversely, the lack of an association with altered glucose levels as IFG or IGT might be secondary to underpowered sample size, being that these conditions a rare event in Caucasian paediatric obese children $(6,55)$.

Lastly, AST and ALT showed a direct association both with cortisol and IGF-I SDS, especially in III and IV quartiles. ALT represents the most specific hepatocyte damage marker, even in paediatric age (56), and liver steatosis is the most common cause for overweight and obese children and adolescents ranging up to $34 \%(56,57)$ and being associated with a lipid profile characterized by hypertriglyceridemia and increased non-HDL cholesterol (58). This has been confirmed by our results. However, it has not been possible to perform abdominal ultrasound or liver biopsy to all enrolled children. Due to this absence of data, the increase of AST and ALT with the liver steatosis remains a hypothesis in this population. Although obesity is strongly associated with hepatic steatosis, an excess of adipose tissue is not the only cause for liver steatosis development. Indeed, patients with lipodystrophy show a marked insulin resistance and easily develop hepatic steatosis and type 2 diabetes, suggesting that it is not the obesity that causes the pathology, making lipolytic activity dysfunction the main factor (59). In our study, this could be justified by the lipolytic effect linked to functional hypercortisolemia associated with higher IGF-I levels suggestive of hyper-nutrition.

This study has several limitations. First, we did not recruit healthy normal-weight children. We tried to overcome this point by investigating a huge cohort composed of overweight, obese, and severely obese children and adolescents in the hypothesis that trends of comorbidities, cortisol, and IGF-I levels were associated with the progressive increase of weight scores. However, we cannot exclude that a control group with and without subtle metabolic alterations could modify some of our findings. Further studies including also healthy children are mandatory to confirm our suggestions. Second, we limited the used quartile-based categories to evaluate the relationship between cortisol/IGF-I and metabolic alterations. While this approach is largely used and generally produces valid results $(60,61,62)$, other options (e.g. flexible modelling of the interaction of continuous variables) are available as well and could produce different results.

Third, the role of hyper-nutrition or unbalanced nutrition on the relationship among IGF-I, cortisol, and cardiometabolic parameters is a hypothesis in our study but also an exciting issue. Recent findings suggest that the adherence to a Mediterranean diet, mainly protein and milk intake are associated with the functionality of the GH/IGF-I axis and the cardiometabolic profile in adult obesity $(63,64)$. Moreover, skipping breakfast, and then reducing milk intake, has been associated with a worse metabolic profile also in paediatric obesity (65). Other foods have been associated with inflammation and may modulate the HPA axis (66). In the view of the role of nutrients as metabolic sensors, a complete picture of food habits is required in further studies. 
In conclusion, this study aimed to establish the association between cortisol, GH/IGF-I axis, and metabolic complications in overweight and obese children and adolescents. We observed that some of the parameters known to be associated with increased cardiovascular risk were related to high levels of IGF-I and cortisol, even if within normal range. We showed that subjects with high IGF-I and cortisol had an increased risk of hypertension, hypercholesterolemia, high levels of triglycerides, and reduced HDL cholesterol. Diversely, lower IGF-I levels were associated with higher blood glucose, insulin, insulin resistance, and reduced insulin sensitivity levels with the rise of cortisol. These data suggest that cortisol and IGF-I play a complex role in the comorbidities of obesity. The evaluation of both variables could clarify some of the discordant results shown in literature on the role of IGF-I.

\section{Supplementary materials}

This is linked to the online version of the paper at https://doi.org/10.1530/ EJE-19-0792.

\section{Declaration of interest}

The authors declare that there is no conflict of interest that could be perceived as prejudicing the impartiality of the research reported.

\section{Funding}

This work was supported by Research Projects of National Interest (PRIN) 2008 (grant number 20082P8CCE).

\section{References}

1 Anagnostis P, Athyros VG, Tziomalos K, Karagiannis A \& Mikhailidis DP. CLINICAL REVIEW: The pathogenetic role of cortisol in the metabolic syndrome: a hypothesis. Journal of Clinical Endocrinology and Metabolism 200994 2692-2701. (https://doi. org/10.1210/jc.2009-0370)

2 Reinher T \& Andler W. Cortisol and its relation to insulin resistance before and after weight loss in obese children. Hormone Research 2004 64 107-112. (https://doi.org/10.1159/000079841)

3 Barat P, Gayard-Cros M, Andrew R, Corcuff JB, Jouret B, Barthe N, Perez P, Germain C, Tauber M, Walker BR et al. Truncal distribution of fat mass, metabolic profile and hypothalamic-pituitary adrenal axis activity in prepubertal obese children. Journal of Pediatrics 2007 150 535-539. (https://doi.org/10.1016/j.jpeds.2007.01.029)

4 Shao S, Zhang X \& Zhang M. Inhibition of 11-beta-hydroxysteroid dehydrogenase type 1 ameliorates obesity-related insulin resistance. Biochemical and Biophysical Research Communications 2016478 474-480. (https://doi.org/10.1016/j.bbrc.2016.06.015)

5 Infante M, Armani A, Mammi C, Fabbri A \& Caprio M. Impact of adrenal steroids on regulation of adipose tissue. Comprehensive Physiology 20177 1425-1447. (https://doi.org/10.1002/cphy.c160037)

6 Prodam F, Ricotti R, Agarla V, Parlamento S, Genoni G, Balossini C, Walker GE, Aimaretti G, Bona G \& Bellone S. High-end normal adrenocorticotropic hormone and cortisol levels are associated with specific cardiovascular risk factors in pediatric obesity: a cross-sectional study. BMC Medicine 201311 44. (https://doi. org/10.1186/1741-7015-11-44)

7 Veldhuis J \& Iranmanesh A. Dual defects in pulsatile growth hormone secretion and clearance subserve the hyposomatotropism of obesity in man. Journal of Clinical Endocrinology and Metabolism 199172 51-59. (https://doi.org/10.1210/jcem-72-1-51)

8 Liang S, Hu Y, Liu C, Qi J \& Li G. Low insulin-like growth factor 1 is associated with low high-density lipoprotein cholesterol and metabolic syndrome in Chinese nondiabetic obese children and adolescents: a cross-sectional study. Lipids in Health and Disease 2016 15 112. (https://doi.org/10.1186/s12944-016-0275-7)

9 Maccario M, Grottoli S, Procopio M, Oleandri SE, Rossetto R, Gauna C, Arvat E \& Ghigo E. The GH/IGF-I axis in obesity: influence of neuro-endocrine and metabolic factors. International Journal of Obesity and Related Metabolic Disorders 200424 S96-S99. (https://doi. org/10.1038/sj.ijo.0801289)

10 Frystyk J, Vestbo E, Skjaerbaek C, Mogensen CE \& Orskov H. Free insulin-like growth factors in human obesity. Metabolism 199544 37-44. (https://doi.org/10.1016/0026-0495(95)90219-8)

11 Gasco V, Pagano L, Prodam F, Marzullo P, Ghigo E \& Aimaretti G. Testing GH in obesity: overweight and obesity as counfounding factors in the diagnosis of adult GH deficiency. In HypothalamicPituitary Disease and Obesity, pp 109-118. Eds DR Clemmons \& AF Attanasio. Bristol: BioScentifica Ltd, 2009.

12 Schneider HJ, Saller B, Klotshe J, Marz W, Erwa W, Wittchen AU $\&$ Stalla GK. Opposite associations of age-dependent insulin-like growth factor-l standard deviation scores with nutritional state in normal weight and obese subjects. European Journal of Endocrinology 2006 154 699-706. (https://doi.org/10.1530/eje.1.02131)

13 Schneider HJ, Klotsche J, Saller B, Böhler S, Sievers C, Pittrow D, Ruf G, März W, Erwa W, Zeiher AM et al. Associations of agedependent IGF-I SDS with cardiovascular diseases and risk conditions: cross-sectional study in 6773 primary care patients. European Journal of Endocrinology 2008158 153-161. (https://doi. org/10.1530/EJE-07-0600)

14 Mora M, Serra-Prat M, Palomera E \& Puig-Domingo M. Metabolic and hormonal contributors to survival in the participants of the Mataró Ageing Study at 8 years follow-up. Clinical Endocrinology 2014 81 775-83. (https://doi.org/10.1111/cen.12467)

15 Mazziotti G \& Giustina A. Glucocorticoids and the regulation of growth hormone secretion. Nature Reviews Endocrinology 20139 265-276. (https://doi.org/10.1038/nrendo.2013.5)

16 Tanner JM. Growth at Adolescence: With a General Consideration of the Effects of Hereditary and Environmental Factors upon Growth and Maturation from Birth to Maturity, 2nd ed. Oxford: Blackwell Scientific Publications, 1962.

17 Cole TJ \& Lobstein T. Extended international (IOTF) body mass index cut-offs for thinness, overweight and obesity. Pediatric Obesity 20127 284-294. (https://doi.org/10.1111/j.2047-6310.2012.00064.x)

18 National High Blood Pressure Education Program Working Group on High Blood Pressure in Children and Adolescents. The fourth report on the diagnosis, evaluation, and treatment of high blood pressure in children and adolescents. Pediatrics 2004114 555-576.

19 Nieman LK, Biller BM, Findling JW, Newell-Price J, Savage MO, Stewart PM \& Montori VM. The diagnosis of Cushing's syndrome: an Endocrine Society Clinical Practice Guideline. Journal of Clinical Endocrinology and Metabolism 200893 1526-1540. (https://doi. org/10.1210/jc.2008-0125)

20 Ricotti R, Genoni G, Giglione E, Monzani A, Nugnes M, Zanetta S, Castagno M, Marolda A, Bellomo G, Bona G et al. High-normal estimated glomerular filtration rate and hyperuricemia positively correlate with metabolic impairment in pediatric obese patients. PLoS ONE 201813 e0193755. (https://doi.org/10.1371/journal. pone.0193755)

21 Genoni G, Menegon V, Secco GG, Sonzini M, Martelli M, Castagno M, Ricotti R, Monzani A, Aronici M, Grossini E et al. 
Insulin resistance, serumuric acid and metabolic syndrome are linked to cardiovascular dysfunction in pediatric obesity. International Journal of Cardiology 2017249 366-371. (https://doi.org/10.1016/j. ijcard.2017.09.031)

22 Cruz ML \& Goran MI. The metabolic syndrome in children and adolescents. Current Diabetes Reports 20044 53-62. (https://doi. org/10.1007/s11892-004-0012-x)

23 Prodam F, Savastio S, Genoni G, Babu D, Giordano M, Ricotti R, Aimaretti G, Bona G \& Bellone S. Effects of growth hormone (GH) therapy withdrawal on glucose metabolism in not confirmed GH deficient adolescents at final height. PLoS ONE 20149 e87157. (https://doi.org/10.1371/journal.pone.0087157)

24 Bornstein SR, Allolio B, Arlt W, Barthel A, Don-Wauchope A, Hammer GD, Husebye ES, Merke DP, Murad MH, Stratakis CA et al. Diagnosis and treatment of primary adrenal insufficiency: an Endocrine Society Clinical Practice Guideline. Journal of Clinical Endocrinology and Metabolism 2016101 364-389. (https://doi org/10.1210/jc.2015-1710)

25 Schaalan M, Waleed M \& Rahmo R. Association of cardiac NT pro-btype natriuretic peptide with metabolis and endothelial risk factors in young obese hypertensive patients: a perpective on the hypothalamic pituitary adrenal axis activation. Diabetology and Metabolic Syndrome 20168 52. (https://doi.org/10.1186/s13098-016-0164-2)

26 Hawkes CP \& Grimberg A. Measuring growth hormone and insulinlike growth factor-I in infants: what is normal? Pediatric Endocrinology Reviews 201311 126-146.

27 Reinehr T, Kleber M, Toschke AM, Woelfle J \& Roth CL. Longitudinal association between IGFBP-1 levels and parameters of the metabolic syndrome in obese children before and after weight loss. International Journal of Pediatric Obesity 20116 236-243. (https://doi.org/10.3109/1 7477166.2010.544739)

28 Adam TC, Hasson RE, Ventura EE, Toledo-Corral C, Le Swapna Mahurkar KA, Lane CJ, Weigensberg MJ \& Goran MI. Cortisol in negatively associated with insulin sensitivity in overweight Latino youth. Journal of Clinical Endocrinology and Metabolism 201095 4729-4735. (https://doi.org/10.1210/jc.2010-0322)

29 Wiegand S, Richardt A, Remer T, Wudy SA, Tomlinson JW, Hughes B, Grüters A, Stewart PM, Strasburger CJ \& Quinkler M. Reduced 11beta-hydroxysteroid dehydrogenase type 1 activity in obese boys. European Journal of Endocrinology 2007157 319-324. (https://doi. org/10.1530/EJE-07-0193)

30 Schutte A, Volpe M, Tocci G \& Conti E. Revisiting the relationship between blood pressure and insulin-like growth factor-1. Hypertension 201463 1070-1077. (https://doi.org/10.1161/ HYPERTENSIONAHA.113.03057)

31 Vitale G, Pivonello R, Auriemma RS, Guerra E, Milone F, Savastano S, Lombardi G \& Colao A. Hypertension in acromegaly and in the normal population: prevalence and determinants. Clinical Endocrinology 200563 470-476. (https://doi.org/10.1111/j.13652265.2005.02370.x)

32 Zarei S, Frieden M, Kaufmann J \& Vischer U. The regulation of endothelial vWF secretion by nitric oxide: is it physiological? Journal of Thrombosis and Haemostasis 20064 263-265. (https://doi. org/10.1111/j.1538-7836.2005.01626.x)

33 Conti E, Musumeci MB, De Giusti M, Dito E, Mastromarino V, Autore C \& Volpe M. IGF-1 and atherothrombosis: relevance to pathophysiology and therapy. Clinical Sciences $2011120377-402$. (https://doi.org/10.1042/CS20100400)

34 Yang Q, Sun M, Ramchandran R \& Usha Raj J. IGF-1 signaling in neonatal hypoxia-induced pulmonary hypertension: role of epigenetic regulation. Vascular Pharmacology 201573 20-31. (https:// doi.org/10.1016/j.vph.2015.04.005)

35 Lampit M, Nave T \& Hochberg Z. Water and sodium retention during short-term administration of growth hormone to short normal children. Hormone Research 199850 83-88. (https://doi. org/10.1159/000023239)
36 Diéz J \& Laviades C. Insulin-like growth factor 1 and collagen type III synthesis in patients with essential hypertension and left ventricular hypertrophy. Journal of Human Hypertension 19948 S21-S25.

37 Diez J, Ruilope LM \& Rodicio JL. Insulin response to oral glucose in essential hypertensives with increased circulating levels of insulin growth factor 1. Journal of Hypertension: Supplement 19919 S174-S175.

38 Succurro E, Andreozzi F, Marini MA, Lauro R, Hribal ML, Perticone F $\&$ Sesti G. Low plasma insulin-like growth factor-1 levels are associated with reduced insulin sensitivity and increased insulin secretion in nondiabetic subjects. Nutrition, Metabolism and Cardiovascular Diseases 200919 713-719. (https://doi.org/10.1016/j. numecd.2008.12.011)

39 van Bunderen CC, Oosterwerff MM, van Schoor NM, Deeg DJ, Lips P \& Drent ML. Serum IGF1, metabolic syndrome, and incident cardiovascular disease in older people: a population-based study. European Journal of Endocrinology 2013168 393-401. (https://doi. org/10.1530/EJE-12-0784)

40 Shibata H, Suzuki H, Maruyama T \& Saruta T. Gene expression of angiotensin II receptor in blood cells of Cushing's syndrome. Hypertension 199526 1003-1010. (https://doi.org/10.1161/01. HYP.26.6.1003)

41 Wallerath T, Witte K, Schafer SC, Schwartz PM, Prellwitz W, Wohlfart P, Kleinert H \& Lehr HA. Down-regulation of the expression of endothelial NO synthase is likely to contribute to glucocorticoidmediated hypertension. PNAS 199996 13357-13362. (https://doi. org/10.1073/pnas.96.23.13357)

42 Guzzetti C, Pilia S, Ibba A \& Loche S. Correlation between cortisol and components of the metabolic syndrome in obese children and adolescents. Journal of Endocrinological Investigation 201437 51-56. (https://doi.org/10.1007/s40618-013-0014-0)

43 Esteghamati A, Morteza A, Khalilzadeh O, Noshad S, Novin L \& Nakhjavani M. Association of serum cortisol levels with parameters of metabolic syndrome in men and women. Clinical and Investigative Medicine 201134 131-137. (https://doi.org/10.25011/cim. v34i3.15185)

44 van Raalte DH, Ouwens DM \& Diamant M. Novel insights into glucocorticoid-mediated diabetogenic effects: towards expansion of therapeutic options? European Journal of Clinical Investigation 200939 81-93. (https://doi.org/10.1111/j.1365-2362.2008.02067.x)

45 Nelson DL \& Cox MM. I principi di biochimica di Lehninger, 5th ed. Zanichelli, 2010.

46 Cianfarani S, Insaghi E, Alisi A, Germani D, Puglianiello A \& Nobili V. Insulin-like growth factor-I and -II levels are associated with the progression of nonalcoholic fatty liver disease in obese children. Journal of Pediatrics 2014165 92-98. (https://doi.org/10.1016/j. jpeds.2014.01.052)

47 Russell M, Bredella M, Tsai P, Mendes N, Miller KK, Klibanski A \& Misra M. Relative growth hormone deficiency and cortisol excess are associated with increased cardiovascular risk markers in obese adolescent girls. Journal of Clinical Endocrinology and Metabolism 2009 94 2864-2871. (https://doi.org/10.1210/jc.2009-0380)

48 Cao WM, Murao K, Imachi H, Yu X, Dobashi H, Yoshida K, Muraoka T, Kotsuna N, Nagao S, Wong NC et al. Insulin-like growth factor-I regulation of hepatic scavenger receptor class BI. Endocrinology 2004145 5540-5547. (https://doi.org/10.1210/ en.2004-0330)

49 Boechem A, Holleboom A, Romijn J \& Hoekstra M. High density lipoprotein as a source of cholesterol for adrenal steroidogenesis: a study in individuals with low plasma HDL-C. Journal of Lipid Research 201354 1798-1704. (https://doi.org/10.1194/jlr.M034264)

50 Illingworth D, Lees A \& Lees R. Adrenal cortical function in homozygous familial hypercholesterolemia. Metabolism 198432 206-211.

51 van der Voort P, Gerritsen R, Bakker A, Boerma E, Kuiper M \& de Heide L. HDL-Cholesterol level and cortisol response to synacthen 
in critically ill patients. Intensive Care Medicine 200329 2199-2203. (https://doi.org/10.1007/s00134-003-2021-7)

52 Daniels SR \& Greer FR. Lipid screening and cardiovascular health in childhood. Pediatrics 2008122 198-208. (https://doi.org/10.1542/ peds.2008-1349)

53 Kumar S \& Kelly A. Review of childhood obesity: from epidemiology, etiology, and comorbidities to clinical assessment and treatment. Mayo Clinic Proceedings 201792 251-265. (https://doi.org/10.1016/j. mayocp.2016.09.017)

54 LeRoith D \& Yakar S. Mechanism of disease: metabolic effects of growth hormone and insulin-like growth factor 1. Nature Clinical Practice: Endocrinology and Metabolism 20073 302-310. (https://doi. org/10.1038/ncpendmet0427)

55 Di Bonito P, Licenziati MR, Baroni MG, Congiu T, Incani M, Iannuzzi A, Maffeis C, Perrone L, Valerio G \& Del Giudice EM. High normal post-load plasma glucose, cardiometabolic risk factors and signs of organ damage in obese children. Obesity 201422 1860-1864. (https://doi.org/10.1002/oby.20787)

56 Kang KS. Abnormality on liver function test. Pediatric Gastroenterology, Hepatology and Nutrition 201316 225-232. (https:// doi.org/10.5223/pghn.2013.16.4.225)

57 Anderson EL, Howe LD, Jones HE, Higgins JP, Lawlor DA \& Fraser A. The prevalence of non-alcoholic fatty liver disease in children and adolescents: a systematic review and meta-analysis. PLOS ONE 2015 10 e0140908. (https://doi.org/10.1371/journal.pone.0140908)

58 Alkhouri N, Eng K, Lopez R \& Nobili V. Non-high-density lipoprotein cholesterol (non-HDL-C) levels in children with nonalcoholic fatty liver disease (NAFLD). Springerplus 20143 407. (https://doi. org/10.1186/2193-1801-3-407)

59 Byrne CD \& Targher G. NAFLD: a multisystem disease. Journal of Hepatology 201562 S47-S64. (https://doi.org/10.1016/j. jhep.2014.12.012)

60 Reynolds RM, Labad J, Strachan MW, Braun A, Fowkes FG, Lee AJ, Frier BM, Seckl JR, Walker BR, Price JF \& Edinburgh Type 2 Diabetes
Study (ET2DS) Investigators. Elevated fasting plasma cortisol is associated with ischemic heart disease and its risk factors in people with type 2 diabetes: the Edinburgh type 2 diabetes study. Journal of Clinical Endocrinology and Metabolism 201095 1602-1608. (https:// doi.org/10.1210/jc.2009-2112)

61 Xie S, Jiang R, Xu W, Chen Y, Tang L, Li L \& Li P. The relationship between serum-free insulin-like growth factor- 1 and metabolic syndrome in school adolescents of northeast China. Diabetes, Metabolic Syndrome and Obesity: Targets and Therapy 201912 305-313. (https://doi.org/10.2147/DMSO.S195625)

62 Ortiz R, Kluwe B, Odei JB, Echouffo Tcheugui JB, Sims M, Kalyani RR, Bertoni AG, Golden SH \& Joseph JJ. The association of morning serum cortisol with glucose metabolism and diabetes: the Jackson Heart Study. Psychoneuroendocrinology 2019103 25-32 (https://doi. org/10.1016/j.psyneuen.2018.12.237).

63 Barrea L, Di Somma C, Macchia PE, Falco A, Savanelli MC, Orio F, Colao A \& Savastano S. Influence of nutrition on somatotropic axis: milk consumption in adult individuals with moderate-severe obesity. Clinical Nutrition 201736 293-301. (https://doi.org/10.1016/j. clnu.2015.12.007)

64 Muscogiuri G, Barrea L, Laudisio D, Di Somma C, Pugliese G, Salzano C, Colao A \& Savastano S. Somatotropic axis and obesity: is there any role for the mediterranean diet? Nutrients 201911 E2228. (https://doi.org/10.3390/nu11092228)

65 Monzani A, Ricotti R, Caputo M, Solito A, Archero F, Bellone $S \&$ Prodam F. A systematic review of the association of skipping breakfast with weight and cardiometabolic risk factors in children and adolescents. what should we better investigate in the future? Nutrients 201911 E387. (https://doi.org/10.3390/ nu11020387)

66 Kirwan AM, Lenighan YM, O’Reilly ME, McGillicuddy FC \& Roche HM. Nutritional modulation of metabolic inflammation. Biochemical Society Transactions 201745 979-985. (https://doi. org/10.1042/BST20160465)

Received 4 October 2019

Revised version received 4 December 2019

Accepted 20 December 2019 